\title{
Research on the Construction of Characteristic Towns in Zhaotong City under the Background of Rural Revitalization Strategy
}

\author{
Min Deng \\ College of Agriculture and Life Sciences, Zhaotong University, Suijiang County, Zhaotong City, Yunnan \\ Province, 657700, China
}

Keywords: Rural revitalization; Zhaotong City; characteristic town; development countermeasures

\begin{abstract}
The proposal of the rural revitalization strategy makes the village keep pace with the city. As an independent variable, the village can stimulate the deep development vitality with its own industrial, ecological, cultural and other resources. This subversive change in decision-making has transformed the rural area from the passive receptor in the past to the active player with vitality at present, thus realizing the reconstruction of urban-rural relations. The construction of characteristic towns is an important starting point and a strong support point for implementing the rural revitalization strategy. It is necessary to lay a new bureau on the industrial system and seek new chapter in the innovative vitality. Based on the author's learning and practical experience, this paper first analyzed the importance of the construction of characteristic towns to the rural revitalization strategy, and then proposed the countermeasures for the development of characteristic towns in Zhaotong under the background of rural revitalization strategy.
\end{abstract}

\section{Introduction}

The 19th National Congress of the Communist Party of China put forward the implementation of rural revitalization strategy, which is the need for comprehensive social and economic development and the need to build a moderately prosperous society in all aspects. Zhaotong City held a promotion meeting for the construction of characteristic towns in the city on July 28, 2017. The meeting pointed out that in the previous stage, under the promotion of the municipal party committee and the municipal government, and with the joint efforts of the city and county, 5 characteristic towns in Zhaotong stood out from more than 290 declared towns in the province, such as Dashanbao and Xiaocaopba. Dashanbao has involved in the list of the first-class characteristic towns in the country. The concept of a characteristic town is not the same as a town or industrial park. The characteristic town is a development space platform that is relatively independent of the urban area and has clear industrial positioning, cultural connotation, tourism and certain community functions.

\section{The Importance of the Construction of Characteristic Towns to the Rural Revitalization Strategy}

The construction of characteristic towns is a systematic project of rural development. It covers urban and rural integration development, rural land system reform, rural collective property rights system reform, modern agricultural industrial system production system management system construction, rural grassroots infrastructure construction and many other tasks. In the process of implementing the rural revitalization strategy and promoting the integration of urban and rural development, we should clarify the relationship between the rural revitalization strategy and the construction of characteristic towns, accurately grasp the connection points, and fully understand the importance and necessity of the construction of characteristic towns in the process of implementing the rural revitalization strategy. Integrating the construction of characteristic towns into the rural revitalization strategy is in line with the development requirements of the 19th National Congress of the Communist Party of China on the issue of agriculture, rural areas and farmers and the concept of building a town with relevant characteristics. It can effectively promote 
the integration and development of primary, secondary and tertiary industries in rural areas and accelerate the process of promoting the modernization of agriculture. The rural areas can further broaden the channels for solving problems of agriculture, rural areas and farmers, and effectively enhance the endogenous development momentum of the rural revitalization strategy. Urban-rural integration development is to revitalize the countryside as an organic unity based on the rural ecological, industrial, cultural, folk and other resource advantages. It focuses on the rural initiative and work enthusiasm to greatly stimulate endogenous motivation and vitality in of the rural development. This will help to build a long-term mechanism that is more conducive to promoting sustainable rural development. The implementation of the rural revitalization strategy requires a starting point and an effective carrier, and the construction of characteristic towns is the starting point and carrier, because the construction of characteristic towns can further integrate the unique natural resources, historical heritage, cultural heritage and customs in space, form and content to create beautiful villages with rich local characteristics and distinctive industrial characteristics, thus promoting rural areas. The development of featured industries lays the foundation for the implementation of the rural revitalization strategy. On one hand, characteristic towns can carry the development of modern agricultural industrial system, production system and management system, and the transfer and accumulation of rural labor. On the other hand, it can also use characteristic towns as a platform to attract urban resources into rural areas to adapt to the living and consumption needs of the urban population and to undertake the spillover of urban population life and consumption, so that urban people can understand homesickness, know homesickness and remember homesickness. This enables rural people to understand the city and integrate into the city to promote urban and rural areas. It will help eliminate the dual structure of urban and rural areas.

According to the Notice on the Construction of Characteristic Towns promulgated by the state, by 2020 the country will build and cultivate about 1,000 characteristic towns with distinctive characteristics and strong vitality, which will drive the leisure tourism and cultural construction, trade and logistics, education and technology, environmental governance and other industrial development of the countryside. It is foreseeable that in the next few years, the whole country will intensify efforts to construct characteristic towns, and there will be more characteristic towns with modern agriculture, leisure industry, tourism, special planting, science and technology, culture, green ecology, business services, and festivals and exhibitions. This will definitely help to promote the smooth implementation of the rural revitalization strategy in Shaotong City.

\section{Countermeasures for the Development of Characteristic Towns in Zhaotong City under the Background of Rural Revitalization Strategy}

\subsection{To deal with three relationships.}

The relationship between characteristic towns and innovation-driven development: agglomerating innovative resources, activating innovation power and transforming innovation achievements can realize the transformation of industrial development from resource-driven one to innovation-driven one. This is the basic goal and task of creating a characteristic town. The characteristic town should be regarded as the new engine and carrier of the innovation-driven strategy. The relationship between the characteristic towns and the transformation and upgrading of the agglomeration area: Although it is different from the industrial parks and industrial clusters, the successful characteristic towns are mostly based on the former. It is necessary to make full use of the secondary development of industrial parks and the opportunity of transformation and upgrading of industrial agglomeration areas to combine the classification gradient cultivation mechanism of characteristic towns to create and upgrade characteristic industrial bases, block economy and industrial clusters. This will provides a rich reserve of the establishment of city-level and provincial characteristic towns. The relationship between the characteristic town and the beautiful village: the characteristic towns are mostly in the urban-rural junction, or on the edge of the township at the end of the city. The planning and construction of characteristic towns can be organically integrated with the surrounding villages to combine with transformation of the old village, water reservation and 
the beautiful village. Through the extension of the characteristic towns and the extension of functions, the industrial development and infrastructure construction will drive regional economic and social development, and the characteristic towns will be regarded as a new platform for strengthening the village-level collective economy and increasing farmers' income, as a platform to optimize rural ecological environment and a new carrier of excavation of culture with rural characteristics.

\subsection{To establish three ecosystems. Governmental ecosystem}

The government plays the role of guider" and "waiter", and pays more attention to government system innovation, policy innovation and work style innovation to create a clean and efficient government ecosystem. The government needs to adhere to the reform, continue to deepen the "four lists of the government power, negative investment of enterprises, government responsibility and special funds management and one network of government service" reform, and reduce articles of the power list and add articles in the list of responsibilities. The government can further reduce the market entry threshold and entrepreneurial threshold, and provide precision and efficient public service for the characteristic towns and their market entities. Entrepreneurial innovation ecosystem: the government needs to focus on creating a collective ecosystem that integrates crowding work space, working teams and the innovation mechanism. We will vigorously support the construction of various new technology innovation public service platforms, such as various incubators, encourage the development of entrepreneurial incubation, early investment, and entrepreneurship education, and focus on supporting innovation and entrepreneurship of undergraduates, overseas returnees, technicians and professional managers. The government will strive to build a collaborative innovation mechanism with politics, production, learning, research, finance, introduction and application to form a cross-region, cross-industry and inter-agency innovation alliance to fully integrate various innovation elements and form a development trend of mutual and spiraling promotion. Natural ecosystem: the government focuses on the harmonious development of buildings, facilities, vegetation, natural environment and other factors in characteristic towns to strive to create a more attractive town ecosystem. All work will fully consider the ecological environment capacity, minimize the impact on the local landscape, hydrological background and regional ecosystems to build a beautiful town with green production, green living, green ecology and green energy. The town will actively develop leisure tourism, sightseeing tourism, industrial tourism, experiential tourism and health tourism to create a model area in Zhejiang province for urban and rural areas.

\subsection{To do a good job in three key tasks.}

To accelerate scientific planning and highlight the characteristic culture: the town needs to pay attention to the cohesiveness of planning, and establish an overall development plan from concept to concrete, from scheming to planning and from whole part to partial part as soon as possible. The construction needs to combine with urban overall planning and land use planning and highlight the characteristic cultural elements. Key projects should be constructed in the core area of the town and a little living room with multiple functions should be built to display the basic situation and history of the town, conduct business activities and receive visitors. To highlight market entities and improve operational management: First, the characteristic town needs to abandon the traditional practice of government investment and attracting investment, and establish a sound scientific decision-making mechanism for industrial selection according to the principle of separation of government and enterprise. The town needs to select investment entities with strength that are in line with development orientation of the town. The investment company should undertake the work of development, construction, investment promotion, external cooperation and management services of the town. The government has focused its efforts on researching the policy that promotes the rapid development of characteristic towns and accelerating the improvement of infrastructure and public services. The second is to give full play to the role of leading enterprises. Characteristic towns, especially manufacturing towns, must introduce leading enterprises with strong market power and financial strength, attach great importance to and give full play to the role of listed 
companies, and give full play to their natural advantages and capabilities in building large projects and laying out industrial chains. Third, for small towns with relatively weak corporate strength, they need to strengthen cooperation between the company and banks, trusts, insurance and other financial institutions, and support the development of entities to form group companies through holding, shareholding, mutual shareholding, PPP and other ways to attract private capital to participate in the town. This will achieve benefit sharing and risk sharing. To transform innovative products and upgrade the industry level: first is to choose a good project. Through the establishment of key customer contact mechanism, investment theme positioning mechanism and information sharing linkage mechanism, we will actively connect with domestic and foreign leading enterprises and large groups. The second is to promote innovation. The town needs to deepen business model and business innovation and encourage enterprises to enhance the innovation chain of products with new formats and new models to win market with business model innovation. This also will enhance efficiency with management innovation and enhance value with products with independent intellectual property rights, high added value and strong market competitiveness to constantly improve the brand image. The third is to attract talents. The town needs to focus on the introduction of overseas talents and leading talents in industries such as 1000 talents in the country and 1000 talents in the province and implement incentive measures such as subsidies for entrepreneurial venues, loan interest subsidies and housing subsidies to stimulate talents. At the same time, we should continue to improve the infrastructure in the town and facilities of the modern service industry to provide a green, environmentally friendly, convenient and comfortable entrepreneurial and innovative environment for entrepreneurial and innovative talents.

Summary There are comparatively rich resources in characteristic towns in Shaotong City and we should fully realize the importance of the construction of characteristic towns to the rural revitalization strategy. In order to speed up the construction of characteristic towns, first of all, we must properly manage the relationship between characteristic towns and innovation-driven development, the transformation and upgrading of cluster areas, and the creation of beautiful villages. Secondly, we must establish a government ecosystem, entrepreneurial innovation ecosystem, and natural ecosystems. Third, we must do a good job in scientific planning, operation management and agglomeration transformation.

\section{Acknowledgments}

Fund project: philosophical and social science project (zt2019002)

\section{References}

[1] Deng Yanping. A Research on the Construction of Characteristic Towns in Jiangxi under the Rural Revitalization Strategy [J]. China Business Theory, 2018, (25): 150-151.

[2] Research Group on the Construction of Characteristic Towns in Liaoning Province. The Characteristic Towns and Creation Paths from the Perspective of Rural Revitalization [J]. Shenyang Cadre Journal, 2018, 20(03): 29-30.

[3] Xu Hong, Wang Caicai. The Trend and Strategies of the Construction of Tourism Characteristic Towns [J]. Tourism Journal, 2018, 33(06): 5-7.

[4] Cao Taiyun. The realistic Dilemma and Solution Strategy of Characteristic Towns under the Rural Revitalization Strategy [J]. Northern Economy and Trade, 2018, (05): 3-4. 